\title{
ASSESSMENT OF FACTORS INFLUENCING FACILITY MANAGEMENT PROCUREMENT ROUTE IN LAGOS STATE, NIGERIA
}

\author{
Faremi Julius.Olajide, Adenuga Olumide.Afolarin, John Iniobong Beauty \\ Department of Building, Faculty of Environmental Sciences, University of Lagos, Akoka, \\ Lagos, Nigeria \\ juliusfaremi@gmail.com
}

\begin{abstract}
Procurement of Facility Management (FM) services can be made through three main approaches; In-sourcing, Outsourcing or a combination of both In-sourcing and Outsourcing (Hybrid). The approach taken depends on the priority set by the organisation for the services to be procured amidst prevailing constraints and limitations. Many organisations follow a rule of chance approach in choosing a particular FM procurement option that seems right at the time and then wait to learn from the outcome later, this no doubt can come at a very high consequence to the organisation. This study therefore assesses the factors influencing the choice of procurement routes in facilities management. 75 structured research questionnaires were distributed, 55 were completed and returned representing a $73 \%$ response rate. The findings of this study shows that continuity and risk management are the most important factors influencing decision when considering in-house procurement route for FM services while reduced overhead and improved process responsiveness were ranked as top factors considered when outsourcing and choosing the hybrid routes respectively. It was recommended that organisations must strive to achieve efficiency in their service delivery for enhanced customer satisfaction.
\end{abstract}

Keywords: Risk, Procurement, Facility Management, Services and Organisations.

\subsection{Introduction}

The decision to procure FM services can be made following three main approaches; Outsourcing, In-house and a combination of both (hybrid). Atkins (2005) posits that the approach taken depends on the priority set by the organisation for the services to be provided. A range of criteria for consideration as part of the decision making process will have to be explored by the organisation which includes but is not limited to the cost of providing the current services, improving process responsiveness and cycle time and identifying cost efficiency routes (Smith, 2003). Outsourcing mostly refers to the development of a new contractual relationship where tasks formerly carried out by in-house employees are transferred to one or more companies pre-existing or created for the purpose. It allows an organisation to focus on its core competencies (Rostamy, 2008) and that the organisation receiving the outsourced operation will already is operating within its core competency. It is a management strategy by which an organisation outsources major, non-core functions to specialized, efficient service providers. It assists companies to level off peaks and valleys in their workload. On the contrary, Barrett (2003) opines that the In-house approach is referred to as service that is provided by a dedicated resource directly employed by the client organisation where monitoring and control of performance is normally conducted under the terms of conventional employer/employee relationship. In-house option is preferable to outsourcing where the provision of the facilities management service requires building skill and knowledge for improved customer service (Wise, 2007). 
There are therefore a number of challenges facing the FM organisations. Foremost is the decision on which service(s) is to be outsourced and which to retain in-house. Many organisations follow a rule of chance approach of simply going ahead with any option which seems right at the time and then wait to learn from the future outcome. Such game of chance can undoubtedly come at very high negative consequences to the organisation. Other challenges include; inadequate funding, insufficient knowledge and risks associated with each choice of procurement route for service delivery. This study aims to assess the factors which organisations should consider when making decision on appropriate procurement routes for facility management services.

\subsection{Research Hypotheses}

The research hypothesis postulated for this study is that there is no significant difference in the factors affecting the choice of outsourcing and in-sourcing facilities management services.

\subsection{Literature Review}

Facilities Management (FM) offers an integrated approach to maintaining, improving and adapting buildings and other infrastructures of an organisation in order to create an environment that strongly supports the primary objectives of the organisation (Strategic Facilities Management Section, SFMS, 2006; Barrett, 2003). FM is essentially a key function in managing facility resources, support services and working environment to support the core business of the organisation in both long term and short-term (Chotipanich, 2004).

FM can be outlined as creating an environment that is conducive to carrying out the organisation's primary operations, taking an integrated view of the services infrastructure and using this to deliver customer satisfaction and best value through support and enhancement of the core business (Atkins and Brooks, 2005). The above perspectives show that the definitions and scope of facilities management and FM services could be wideranging. It is in recognition of this that Kelly, (2002) concluded that, "FM could mean different things to different parties, and the scope of services may vary between organisations or departments". However presented, Atkin and Brooks (2005) argue that a holistic definition of FM should emphasize on the importance of integrative, interdependent disciplines whose overall purpose is to sustain an organisation in the pursuit of its business or objectives. This means that the FM service should aim to accomplish; supporting people in their work and other activities, enhance individual well being, enable the organisation to deliver effective and responsive services, 'Sweat' the physical assets to make them highly cost effective, allow for the future change in the use of space, provide the competitive advantage to the organisation's core business and enhance the organisation's culture and images.

\subsection{In-House Or Outsourcing: Decision Factors}

The role of facilities management has gradually evolved from merely helping the organisation to survive, to a platform that enhances organisations potential to prosper in a volatile commercial climate. It then follows that 
the challenge for facilities managers is indeed the same challenge facing the organisation. Atkins and Brooks (2005) emphasises that these extensive facilities management functions may be successfully performed or provided either by in-house or outsourcing approach, depending on the priority of the activities or services of an organisation. Two possible options exist in the decision to outsource or not to outsource: The organisation decides to retain or outsource the services on the whole basis, or the organisation outsources part of the services and retains certain services in-house (particularly if the FM function is part of the organisational strategic management process).

Atkin (2003) observed that some organisations operate what might be described as a mixed economy, retaining some services in-house whilst contracting out others. Barrett (2005) re-echoed this observation by stating that some organisations favour a totally in-house option, while others literally contract out every service possible; yet others use a combination of both. The decision should be made having regard to the path that leads to longterm value for the organisation. This is achieved by taking full account of the implications, especially the true cost of all options (Atkins and Brooks, 2005).

The decision to outsource or retain FM in-house should be arrived at by answering a number of important questions about the organisations core competencies and policy goals, coupled with the availability of service providers, contract negotiations, and other considerations. It should include identifying an organisation's needs, strategic interests and goals, in addition to computing all costs associated with the outsourcing process. In stressing the importance of decision-making, Barrett \& Baldy (2003) stated that the effectiveness of decisions is determined predominantly by the quality of the decision-making process used to generate it and it is usually best for top management to define the decision-making model to be adopted.

Outsourcing is a strategic tool, and if used appropriately, it can generate significant improvements in service and cost for many organisations. Done well, it guarantees an improved understanding of the services provided and their costs. Most importantly, it allows a company to redirect time and resources to its core competency. At the same time, a well-run in-house operation could conceivably operate at 10 to 15 percent less than an outside organisation, simply because it does not have to generate a profit. A sourcing decision can be made by taking into account both the scope and purpose of sourcing (Kakabadse, 2000).

Many factors may impact on an outsourcing decision and these are grouped into four categories of Strategy, Cost, Function characteristics and Environment. Strategic factors include core competencies, critical knowledge, lack of internal human resource, impact on quality and flexibility. Function characteristics include complexity, degree of integration, structure and asset specificity. Environment functions include the internal and external environment faced by the organisation. In a broader perspective, Greaver (2007) posits that the priority of outsourcing depends on which chair one sits. Outsourcing requires professional and strategic manner approach as it has long term inferences. 


\subsection{Research Methods}

This study was aimed at three categories of respondents as sample of the entire population of this study, the client organisations (small, medium and large) requiring FM services, the service provider organisations and the end users of FM services. Asika (2008) define a sample as a good representative of the population. It is regarded as a specimen or part of a whole population. For the client organisation, key personnel that are involved in the decision making concerning FM procurement routes were the targeted respondents. On the part of the service providers, a list of over 100 FM service provider firms was obtained from International Facility Management Association (IFMA), Lagos state chapter. Only 40 of the firms on the list have head offices in Lagos State. Using a table of random numbers, $25 \mathrm{FM}$ service providers firm were selected. This is to ensure that no particular organization or individual is given preference over the others and to avoid a cluster of samples. A structured questionnaire was designed and administered as the principal instrument for obtaining responses from the respondents. Out of the 75 copies of research questionnaire distributed, 55 were completed and returned representing a $73 \%$ response rate. The returned copies were scrutinized for errors, omissions, completeness and inconsistencies and were found to be adequately completed and therefore used to carry out the analysis. Data for the study was processed and analysed with the aid of the Statistical Packages for Social Science. Frequency tables, mean item score and chi-square test were used in this study as descriptive and inferential statistics respectively.

\subsection{Data Presentation And Analysis}

Table 1 shows the designation of respondents within the organisation. Project supervisors constitute the highest proportion $(40.0 \%)$ of the respondents indicating their high involvement in the execution process of facilities management activities in various firms. Both facilities managers and contracts managers account for $58.2 \%$ of the total population with other designations constituting a very minute part of the total population. Table 2 reveals that respondents with the BSc academic qualification constitute the highest proportion of the total population of respondents (47.3\%) meaning, they are the most encountered in organisations, respondents with the HND/OND academic qualification are next in proportion (30.9\%) followed by those with PhD qualification $(12.7 \%)$. This indicates that respondents with adequate academic knowledge were sought out to provide useful information for the purpose of this study.

Table 1: Designation of respondent

\begin{tabular}{lccc}
\hline & Frequency & Percent $(\%)$ & Cumulative Percent $(\%)$ \\
\hline Facilities manager & 20 & 36.4 & 36.4 \\
Project supervisor & 22 & 40.0 & 76.4 \\
Contracts manger & 12 & 21.8 & 98.2 \\
Others & 1 & 1.8 & 100.0 \\
Total & 55 & 100.0 & \\
\hline
\end{tabular}


Table 2: Academic qualification of respondents

\begin{tabular}{lccc}
\hline & Frequency & Percent (\%) & Cumulative Percent (\%) \\
\hline $\mathrm{PhD}$ & 7 & 12.7 & 12.7 \\
$\mathrm{MSc}$ & 5 & 9.1 & 21.8 \\
$\mathrm{BSc}$ & 26 & 47.3 & 69.1 \\
$\mathrm{HND} / \mathrm{OND}$ & 17 & 30.9 & 100.0 \\
Total & 55 & 100.0 & \\
\hline
\end{tabular}

Table 3 displays the professional affiliation of respondents that provided information for this study. Respondents with the IFMA affiliation constitute the highest percentage of respondents (27.3\%) while respondents with the NIESV, PMP, NIOB and other professional affiliations constitute $23.6 \%, 20.0 \%, 12.7 \%$ and $16.4 \%$ respectively. This shows that respondents with a working knowledge of the facilities management practice were approached to provide information to assist in this research work. Table 4 indicates the type of organisation each respondent works for. To assist in the generation of adequate data for the research work, three categories of organisations were sampled, consisting of the client organisations, the FM service providers and the end user organisations. Respondents in the FM service provider firms constitute a major part of the total population accounting for (47.3\%) while the client organisation, end user firms and those outside the pre-defined three groups made up the remaining $(50.9 \%)$ of the total population of the study.

Table 3: Professional qualification of respondents

\begin{tabular}{lccc}
\hline & Frequency & Percent (\%) & Cumulative Percent (\%) \\
\hline NIOB & 7 & 12.7 & 12.7 \\
NIESV & 13 & 23.6 & 36.4 \\
IFMA & 15 & 27.3 & 63.6 \\
PMP & 11 & 20.0 & 83.6 \\
Others & 9 & 16.4 & 100.0 \\
Total & 55 & 100.0 & \\
\hline
\end{tabular}

Table 4: Type of organisation

\begin{tabular}{lccc}
\hline & Frequency & Percent $(\%)$ & Cumulative Percent (\%) \\
\hline Client Organisation & 17 & 30.9 & 30.9 \\
FM service provider & 26 & 47.3 & 78.2 \\
End user & 11 & 20.0 & 98.2 \\
Others & 1 & 1.8 & 100.0 \\
Total & 55 & 100.0 & \\
\hline
\end{tabular}

The next table (Table 5) shows the frequency of application of the various FM procurement routes by organisations. Three (3) major routes were considered which are In-house, Outsourcing and Hybrid (combination of both) procurement routes. From the study, it can be seen that the Hybrid route is the most frequently used option with a mean score of 3.72, followed by the Outsourcing method of procurement route, mean score 3.59. The In-house option is considered the least frequently applied route for procuring FM services, with a mean score of 3.20. This explains the fact that most organisations carry out their FM related services 
using the Hybrid route, this combines the characteristics of both the in-house and outsourcing methods. The objective of this study is to assess and rank the factors influencing the choice of procurement route in facilities management. For the purpose of this study, three major routes have been identified and considered in relation to 26 hypothesised factors capable of influencing the choice of procurement route. Each of these routes is considered and the factors are ranked on the basis of the mean score.

Table 5: Mean score of the frequency of use of procurement routes

\begin{tabular}{lccc}
\hline & $\mathrm{N}$ & Mean & Rank \\
\hline Hybrid & 54 & 3.72 & 1 \\
Outsourcing & 54 & 3.59 & 2 \\
In-house & 54 & 3.20 & 3 \\
\hline
\end{tabular}

Table 6 presents the mean score of factors affecting the choice of outsourcing. Among the factors considered, reduced overhead ranks the highest with a mean score of 4.20, indicating it as a very important factor influencing the choice of an organisation adopting the outsourcing method of procurement for its FM services. Most organisations seek to reduce their expenses on their staff strength and channel the resources saved towards achieving other organisational objectives and as such, strengthening FM service providers who can perform these same services at a faster pace and who have gained expertise in their field of operation. Knowledge and support gained, efficiency, expertise, continuity and risk management also rank as important factors to be considered when adopting the outsourcing procurement route. Innovation, cost reduction, specialization and diversity rank as the least important factors affecting choice of outsourcing. Organisations adopting outsourcing have little or no need for innovating their service provision as this responsibility is already transferred to a service provider, cost reduction is not necessarily achieved in outsourcing as charges can tend to be high due to the fact that service providers operate at a profit margin that may not be covered by the amount saved from reduced overhead. Specialization and diversity, the factor considered the least important explains the fact that organisations that outsource their services can never build a special skill in that field therefore making specialization a very difficult aim to achieve.

Table 7 shows the mean score of factors influencing the choice of In-house option. Continuity and risk management with a mean score of 4.20 rank the most important factor influencing the choice of adopting the Inhouse option. Focus on core values or competencies and accountability also rank as highly important factors influencing this choice with mean scores of 4.03 and 4.00 respectively. An organisation that performs all of its own facilities management services in-house is able to develop laid down procedures for executing work, learn from past mistakes and build up on knowledge gained from previous jobs done.

This helps an organisation to pass on knowledge to new members of staff, pick up on projects not previously completed easily thereby greatly reducing risks of knowledge gaps in processes. It helps organisations to focus on their core values as they build up a professional team and encourages an adequate accountability process. Reduced overhead, cost reduction and cultural changes with mean scores of 2.40, 2.34 and 2.17 respectively. These ranked as the least important factors in the choice of adopting the in-house option. Resources are 
maintained in-house resulting in increased staff overhead costs for the organisation, investments in assets will also build up the cost of an organisation executing its services in-house thereby eliminating the potential opportunity of cost reduction however an organisation may proceed to drive its FM function in-house because the organisation gets to maintain its cultural views and the risk of influence from external service providers which may result in a gradual cultural change in the organisation is eliminated.

Table 6: Mean score of factors influencing the choice of outsourcing FM services

\begin{tabular}{|c|c|c|c|}
\hline & $\mathrm{N}$ & Mean & Rank \\
\hline Reduced overhead & 20 & 4.20 & 1 \\
\hline Knowledge and support gained & 20 & 4.15 & 2 \\
\hline Efficiency & 20 & 4.10 & 3 \\
\hline Expertise & 20 & 4.10 & 3 \\
\hline Continuity and risk management & 20 & 4.10 & 3 \\
\hline Time of delivery & 20 & 4.05 & 6 \\
\hline Service quality & 20 & 4.05 & 6 \\
\hline Degree of system complexity & 20 & 4.00 & 8 \\
\hline Availability of in-house labour force & 20 & 4.00 & 8 \\
\hline Responsibility & 20 & 4.00 & 8 \\
\hline Effectiveness & 20 & 4.00 & 8 \\
\hline Staffing flexibility & 20 & 3.95 & 12 \\
\hline Information & 20 & 3.85 & 13 \\
\hline Customer orientation/ satisfaction & 20 & 3.85 & 13 \\
\hline Competitiveness & 20 & 3.85 & 13 \\
\hline Competence & 20 & 3.85 & 13 \\
\hline Improve process responsiveness and cycle time & 20 & 3.80 & 17 \\
\hline Investment in asset & 20 & 3.80 & 17 \\
\hline Speed & 20 & 3.80 & 17 \\
\hline Developing internal staff & 20 & 3.75 & 20 \\
\hline Cultural change & 20 & 3.75 & 20 \\
\hline Accountability & 20 & 3.75 & 20 \\
\hline Focus on core values or competencies & 19 & 3.74 & 23 \\
\hline Innovation & 20 & 3.70 & 24 \\
\hline Cost reduction & 20 & 3.60 & 25 \\
\hline Specialization and diversity & 20 & 3.55 & 26 \\
\hline
\end{tabular}

Table 8 is a presentation of the mean score of factors affecting choice of the hybrid procurement route. It can be seen from the table that developing internal staff ranks the highest, 4.70, followed by improving process responsiveness and cycle time, 4.20 and efficiency, 4.00. This goes to show that the hybrid process encourages organisations to develop their staff to be able to work within and with the organisations service providers. This as seen from the study will improve process responsiveness, faster work delivery and greater efficiency of work done. Those factors considered to be the least important in the choice of the hybrid route are, specialization and diversity, investment in asset and reduced overhead with mean scores of 2.80, 2.60 and 2.20 respectively. This is due to the fact that these organisations are not aiming to be sole providers of the services they execute in hybrid form; they do not need to build special skills in this field. These types of organisations are not required to 
employ staff directly as they can operate using a service provider's employees, thereby reducing costs and redirecting funds for investing in assets to other core activities.

Table 7: Mean score of factors influencing the choice of in-sourcing FM services

\begin{tabular}{llll}
\hline & N & Mean & Rank \\
\hline Continuity and risk management & 35 & 4.20 & 1 \\
Focus on core values or competencies & 35 & 4.03 & 2 \\
Accountability & 35 & 4.00 & 3 \\
Availability of in-house labour force & 35 & 3.89 & 4 \\
Responsibility & 35 & 3.77 & 5 \\
Developing internal staff & 35 & 3.77 & 5 \\
Service quality & 35 & 3.71 & 5 \\
Effectiveness & 35 & 3.69 & 8 \\
Investment in asset & 35 & 3.69 & 8 \\
Customer orientation/ satisfaction & 35 & 3.66 & 10 \\
Expertise & 35 & 3.57 & 11 \\
Knowledge and support gained & 35 & 3.54 & 12 \\
Staffing flexibility & 35 & 3.51 & 13 \\
Competitiveness & 35 & 3.49 & 14 \\
Efficiency & 35 & 3.43 & 15 \\
Specialization and diversity & 35 & 3.43 & 15 \\
Information & 35 & 3.37 & 17 \\
Time of delivery & 35 & 3.26 & 18 \\
Speed & 35 & 3.26 & 18 \\
Competence & 35 & 3.20 & 20 \\
Innovation & 35 & 3.11 & 21 \\
Improve process responsiveness and cycle time & 35 & 3.00 & 22 \\
Degree of system complexity & 35 & 2.83 & 23 \\
Reduced overhead & 35 & 2.40 & 24 \\
Cost reduction & 35 & 2.34 & 26 \\
Cultural change & 35 & 2.17 & \\
\hline & & & 25 \\
\hline
\end{tabular}

\subsection{Test Of Hypothesis}

To further evaluate the factors influencing the choice of procurement option for executing FM services, Chisquare test was used to test the postulated hypothesis. The results shows that focus on core competencies, cost reduction, speed, innovation, service quality, efficiency, effectiveness, developing internal staff, competence, cultural change, time of delivery, information, specialization and diversity, accountability, customer orientation/satisfaction, investment in asset, competitiveness and availability of in-house labour force have lower calculated chi-square values $\left(\chi^{2} \mathrm{cal}=2.000,4.667,5.556,5.353,4.667,1.333,6.000,3.778,4.667,2.000\right.$, $6.444,2.333,4.667,0.333,1.333,2.889, \& 4.667$ respectively) than their tabulated values ( $\chi^{2}$ tab $\left.=5.991,7.815\right)$ as depicted in the table 9 below. This means that the null hypothesis $\left(\mathrm{H}_{0}\right)$ is to be accepted in all cases. 
Meanwhile, staffing flexibility, knowledge and support gained, reduced overhead, continuity and risk management, expertise, responsibility, improve process responsiveness and cycle time and degree of system complexity have their calculated chi-square $\left(\chi^{2}\right.$ cal $=6.333,10.889,13.556,10.000,8.222,10.889,17.111 \&$ 11.444 respectively) higher than their tabulated values $\left(\chi^{2}\right.$ tab $=5.991,7.815$ and 9.488). This means that the alternative hypothesis $\left(\mathrm{H}_{1}\right)$ is to be accepted in all cases.

Table 8: Mean score of factors influencing the choice of hybrid procurement option

\begin{tabular}{|c|c|c|c|}
\hline & $\mathrm{N}$ & Mean & Rank \\
\hline Developing internal staff & 10 & 4.70 & 1 \\
\hline Improve process responsiveness and cycle time & 10 & 4.20 & 2 \\
\hline Efficiency & 10 & 4.00 & 3 \\
\hline Speed & 10 & 3.90 & 4 \\
\hline Accountability & 10 & 3.80 & 5 \\
\hline Competence & 10 & 3.80 & 5 \\
\hline Competitiveness & 10 & 3.70 & 7 \\
\hline Continuity and risk management & 10 & 3.60 & 8 \\
\hline Innovation & 10 & 3.60 & 8 \\
\hline Expertise & 10 & 3.50 & 10 \\
\hline Knowledge and support gained & 10 & 3.50 & 10 \\
\hline Cost reduction & 10 & 3.50 & 10 \\
\hline Focus on core values or competencies & 10 & 3.50 & 10 \\
\hline Time of delivery & 10 & 3.40 & 14 \\
\hline Effectiveness & 10 & 3.40 & 14 \\
\hline Availability of in-house labour force & 10 & 3.40 & 14 \\
\hline Cultural change & 10 & 3.40 & 14 \\
\hline Customer orientation/ satisfaction & 10 & 3.40 & 14 \\
\hline Information & 10 & 3.30 & 19 \\
\hline Service quality & 10 & 3.20 & 20 \\
\hline Degree of system complexity & 10 & 3.10 & 21 \\
\hline Responsibility & 10 & 2.90 & 22 \\
\hline Staffing flexibility & 10 & 2.90 & 22 \\
\hline Specialization and diversity & 10 & 2.80 & 24 \\
\hline Investment in asset & 10 & 2.60 & 25 \\
\hline Reduced overhead & 10 & 2.20 & 26 \\
\hline
\end{tabular}

\subsection{Summary Of Findings}

From the analysis of data collected, it was discovered that in the decision to choose an appropriate procurement route, organisations will consider those factors that are very important to their continued existence and growth. This study revealed that for the In-house option of procurement, top ranked factors include continuity and risk management, focus on core values and accountability. Organisations adopting the outsourcing option will consider reduced overhead, knowledge and support gained and efficiency as very important factors while those adopting the hybrid option will consider developing internal staff, improve process responsiveness and cycle 
time as well as efficiency as very important factors affecting before concluding on a choice. The analysis of this study further revealed that efficiency is an influencing factor common to both outsourcing and hybrid procurement routes. Also, for all the three procurement routes, reduced overhead and cost reduction was seen as factors not so important, this may be premised on the fact that every organisation need to release its financial resources in the execution of services before any form of results or profit can be generated.

Table 9: Chi-square results of factors influencing outsourcing decision of FM services

\begin{tabular}{llllcl}
\hline Variable of Measurement & $\chi^{2}$ cal & $\chi^{2}$ tab & P value & Sig & Decision \\
\hline Focus on core competencies & 2.000 & 7.815 & 0.572 & NS & Accept $\mathrm{H}_{0}$ \\
Cost reduction & 4.667 & 7.815 & 0.198 & NS & Accept $\mathrm{H}_{0}$ \\
Speed & 5.556 & 7.815 & 0.135 & $\mathrm{NS}$ & Accept $\mathrm{H}_{0}$ \\
Innovation (access to new products \& emerging & 5.353 & 7.815 & 0.148 & $\mathrm{NS}$ & Accept $\mathrm{H}_{0}$ \\
technology & 4.667 & 7.815 & 0.198 & $\mathrm{NS}$ & Accept $\mathrm{H}_{0}$ \\
Service quality & 6.333 & 5.991 & 0.042 & $\mathrm{~S}$ & Accept $\mathrm{H}_{1}$ \\
Staffing flexibility & 1.333 & 5.991 & 0.513 & $\mathrm{NS}$ & Accept $\mathrm{H}_{0}$ \\
Efficiency & 6.000 & 7.815 & 0.112 & $\mathrm{NS}$ & Accept $\mathrm{H}_{0}$ \\
Effectiveness & 10.889 & 7.815 & 0.012 & $\mathrm{~S}$ & Accept $\mathrm{H}_{1}$ \\
Knowledge and support gained & 13.556 & 7.815 & 0.004 & $\mathrm{~S}$ & Accept $\mathrm{H}_{1}$ \\
Reduced overhead & 10.000 & 7.815 & 0.019 & $\mathrm{~S}$ & Accept $\mathrm{H}_{1}$ \\
Continuity and risk management & 3.778 & 7.815 & 0.286 & $\mathrm{NS}$ & Accept $\mathrm{H}_{0}$ \\
Developing internal staff & 4.667 & 7.815 & 0.198 & $\mathrm{NS}$ & Accept $\mathrm{H}_{0}$ \\
Competence & 2.000 & 7.815 & 0.572 & $\mathrm{NS}$ & Accept $\mathrm{H}_{0}$ \\
Cultural change & 8.222 & 7.815 & 0.042 & $\mathrm{~S}$ & Accept $\mathrm{H}_{1}$ \\
Expertise & 6.444 & 7.815 & 0.092 & $\mathrm{NS}$ & Accept $\mathrm{H}_{0}$ \\
Time of delivery & 2.333 & 5.991 & 0.311 & $\mathrm{NS}$ & Accept $\mathrm{H}_{0}$ \\
Information & 2.333 & 5.991 & 0.311 & $\mathrm{NS}$ & Accept $\mathrm{H}_{0}$ \\
Specialization and diversity & 4.667 & 7.815 & 0.198 & $\mathrm{NS}$ & Accept $\mathrm{H}_{0}$ \\
Accountability & 0.333 & 5.991 & 0.846 & $\mathrm{NS}$ & Accept $\mathrm{H}_{0}$ \\
Customer orientation/ satisfaction & 1.333 & 5.991 & 0.513 & $\mathrm{NS}$ & Accept $\mathrm{H}_{0}$ \\
Investment in asset & 10.889 & 7.815 & 0.012 & $\mathrm{~S}$ & Accept $\mathrm{H}_{1}$ \\
Responsibility & 17.111 & 7.815 & 0.001 & $\mathrm{~S}$ & Accept $\mathrm{H}_{1}$ \\
Improve process responsiveness and cycle time & 2.889 & 7.815 & 0.409 & $\mathrm{NS}$ & Accept $\mathrm{H}_{0}$ \\
Competitiveness & 4.667 & 7.815 & 0.198 & $\mathrm{NS}$ & Accept $\mathrm{H}_{0}$ \\
Availability of in-house labour force & 11.444 & 9.488 & 0.022 & $\mathrm{~S}$ & Accept $\mathrm{H}_{1}$ \\
Degree of system complexity & & & & &
\end{tabular}

\subsection{Discussion Of Findings}

Following the analysis of data collected, this study identifies efficiency of the service delivery process, continuity and risk management as major factors affecting the choice of procurement route which an 
organisation may toll or adopt. This correlates with a previously conducted study by Harland (2005) which posit that the levels of satisfaction is a major factor affecting the choice of procurement route been adopted by organisations. These two studies are however in contrast to a similar study carried out by Chan (2012) which shows practical skills of in-house personnel and expertise from outsourcing as the major factors influencing the choice of procurement route organisations adopts.

It is evident that in the face of the need for organisations to optimised resources and the availability of procurement options for FM services, senior management of organisations are saddled with the responsibility of attaining a balance among the crucial factors influencing decisions on FM procurement route as articulated in this study and in previous studies already cited. If these factors are well balanced, firms/organisations can achieve optimal benefits and sustainable competitive advantage among competitors in the industry.

\subsection{Conclusion And Recommendation}

This study has been able to assess the factors influencing the options of procuring Facilities Management Service; it has been able to capture the consideration parameters that inform organisations decision on Insourcing or Outsourcing FM services either in totality or in part.

Some recommendations have also been proposed based on the findings and conclusions made in this study. The researcher is convinced that these recommendations when implemented will assist organisations when deciding on the procurement route to adopt for FM services and also enhance the performance of organisations in effective delivery of FM services.

This study therefore concludes as follows:

The choice of a procurement option for FM services in any given organisation should be premised on the attainment of efficient service delivery which should align with the organisation's corporate objectives. The analysis of this study has shown for example that the In-house option of procurement for FM services is most suited for organisations seeking to focus on preserving the organisations cultural values and promoting value integration through continuity and risk management across the organisation.

Organisations should strive to achieve efficiency in service delivery; this will enhance customer satisfaction, develop staff knowledge and support gained and also improve process responsiveness and cycle time.

Performance is a major factor that will affect the choice of which procurement route to adopt. The way it is handled in every organisation in terms of monitoring and reward for performance will affect employee relationship and passion for the work. It can either reinforce an outsourcing relationship or enhance an in-house retaining of service. When performance is considered in the hybrid option, it can lead to a redundancy in FM roles as well as an excessive monitoring of performance. 
Organisations should ensure that there are established procedures for service procurement before considering the outsourcing or hybrid option because a problem of blank procedures can lead to a risk of non accountability and high levels of business uncertainties.

From the results of this study, it clearly shows that most organisations will procure activities that are core to their business existence through the in-house option for obvious reasons such as; promotion of organisational growth and development, effective management of vital organisation information and easy control of all the activities of the organisation.

\subsection{References}

Alexander, K (2004). Facilities Management: Theory and Practice. London, New York: E\&FN Spoon.

Atkin, B. \& Brooks, A. (2005). Total Facilities Management ( $2^{\text {nd }}$ ed.). Oxford: Blackwell Publishing Ltd.

Atkin, B. (2003). Contracting Out or Managing Services In-house. Nordic Journal of Surveying and Real Estate Research: Special series, 1 .

Atkin, B. and Brooks, A. (2009), Total Facilities Management, 3rd edition, Wiley-Blackwell

Barrett, P. \& Baldry, D. (2003). Facilities Management: Towards best practice ( $2^{\text {nd }}$ ed.). Oxford: Blackwell Publishing Ltd.

Barrett, P. \& Baldry, D. 2003. Total Facilities Management. Oxford: Blackwell Science Limited.

Chan, K. (2012). Critical Factors in Contract Management. Construction Economics and Management 1. Rome.

Charles, KA, Cloete 2004 "Criteria for outsourcing of facilities management functions by the United nations".

Chotipanich, S. (2004). Positioning facilities management. Facilities, 22 (13/14), pp.364-372.

Cloete, C. 2002. Introduction to Facilities Management. Sandton: South Africa Property Education Trust.

Collins, T. (2007). Building and Operations Management. Paper presented at the NZPI CPD Seminar 2007, Wellington, April 2007.

Connors, P. (2003). Innovation Process and Innovativeness in Facility Management Organisations- Comparative Case Study, Wageningen University, Netherlands. 
Gilley, K.M \& Rasheed, A. (2000). Making More by Doing Less: An Analysis of Outsourcing and its Effects on Firm Performance. Journal of Management, 26(4), pp. 763-790.

Hamilton, B. (2004). Recent Trend in Facilities Management. Paper presented at the international Construction Conference 2004.

Harland, C., L. Knight, et al. (2005). "Outsourcing: assessing the risks and benefits for organisations, sectors and nations." International Journal of Operations \& Production Management 25(9): 831-850.

Kakabadse, N. and Kakabadse, A. (2000b), "Critical review - outsourcing: a paradigm shift", The Journal of Management Development, Vol. 19 No. 8, pp. 670-728.

Kelly, J., Morledge, R. \& Wilkinson, S. (2002) Best value in construction. Oxford: Blackwell Science Ltd.

Kishore, R., H. R. Rao, et al. (2003). "A relationship perspective on IT outsourcing." Commun. ACM 46(12): 8692.

Lam, T.Y.M. (2008), “Optimisation of performance management for housing services”, Journal of Facilities Management, Vol. 6 No. 3, pp. 226-40.

McIvor, R. (2011). "Outsourcing done right." Industrial Engineer: 30-35.

Nutt,B. (2004). Infrastructure and facilities: forging alignments between supply and demand: cited in Chotipanich, S. (2004) Positioning facilities Management. Facilities, 22(13/14), pp.364-372.

Pitt, M. and Price, S. (2011), Implications of a sustainability policy for facilities management organisations, Facilities, 29(9/10), 391-410

Rajabzadeh, A., A. A. A. Rostamy, et al. (2008). "Designing a generic model for outsourcing process in public sector: Evidence of Iran." Management Decision 46(4): 521-538.

Tay, L. \& Ooi, J.T.L. (2001). Facilities Management: a ‘jack of all trades’? Facilities, 19 (10), pp. 357-62

Usher, N. (2004). Outsource or in-house facilities management: The Pros and Cons. Journal of Facilities Management, 2(4);ABI/INFORM Global; pp. 351-359.

Wise, D. (2007). Agility Spotlight and leadership in Project Management. Project Management Institute (PMI), PP. 60-61. 